\title{
Disaggregating ecosystem service values and priorities by wealth,
} age, and education

\author{
*Jacqueline D. Lau ${ }^{1}$, Christina C. Hicks ${ }^{2}$, Georgina G. Gurney ${ }^{1}$, Joshua E. Cinner ${ }^{1}$ \\ ${ }^{1}$ Australian Research Council Centre of Excellence for Coral Reef Studies, James Cook \\ University, Townsville, QLD 4811 Australia \\ ${ }^{2}$ Lancaster Environment Centre, Lancaster University, Lancaster, LA5 9PT, UK \\ * Jacqueline Lau, Australian Research Council Centre of Excellence for Coral Reef Studies, \\ 21 James Cook University, QLD 4811 Australia \\ Email: jacqueline.lau@my.jcu.edu.au \\ Ph: +61403990738
}

\begin{abstract}
Ecosystem services support the livelihoods and wellbeing of millions of people in developing countries. However, the benefits from ecosystem services are rarely, if ever, distributed equally within communities. Little work has examined whether and how socio-economic characteristics (e.g. age, poverty, education) are related to how people value and prioritize ecosystem services. We interviewed 372 people connected to coral reef fisheries in 28 communities across four countries in the western Indian Ocean. Each fisher ranked the importance of nine ecosystem service benefits, and then rated which services they most desired an improvement in quantity or quality. We disaggregated their responses to see whether age, poverty, or years of formal schooling influence how fishers rank and prioritize coral reef ecosystem services. Overall, we found little empirical evidence of strong differences between groups. However, the wealthiest fishers did prioritize improvements in habitat ecosystem services and recreational benefits more than other fishers. Our findings emphasize that people directly dependent on coral reef fisheries for their livelihood hold mostly similar values and priorities for ecosystem services. However, poverty influences whether fishers prioritize improvements in supporting ecosystem services associated with environmental care, in this case habitat benefits. Making the differences and similarities between the importance of and priorities for ecosystem services explicit can help decision-makers to target and frame management to be more socially inclusive and equitable and therefore, more effective.
\end{abstract}

\section{Key words}

Poverty, ecosystem services, social differentiation, coral reefs, fisheries

\section{Word count \\ 5525}




\section{Introduction}

Ecosystem service research has made much progress toward conceptualizing and valuing nature's benefits to people. People need nature's benefits to live healthy, fulfilling lives with fresh water, clean air, and nutritious food (MA, 2005). Yet until the $1990 \mathrm{~s}$, these benefits were often undervalued or completely missing from policy (Costanza et al., 1997). Natural capital and ecosystem services thinking emerged to remedy this oversight by explicitly accounting for nature's benefits to people (Daily, 1997). Since the 1990s, ecosystem services research has grown exponentially (Gómez-Baggethun et al., 2010; van den Belt and Stevens, 2016). More recently, a range of institutions and programmes have emerged around ecosystem services research, aiming to contribute to poverty alleviation and enhance human wellbeing. For instance, the Millennium Ecosystem Assessment (MA, 2005), Ecosystem Services for Poverty Alleviation (ESPA), and the International Panel for Biodiversity and Ecosystem Services (IPBES) all focus on improving and safeguarding human wellbeing. This agenda is particularly crucial in developing countries, where people often directly depend on ecosystem services for their sustenance and livelihoods.

Although research has examined the myriad ways that ecosystem services benefits are linked to human wellbeing and poverty alleviation (MA, 2005), the links are not straightforward and remain poorly understood (Fish et al., 2016; Fisher et al., 2014, 2013; Howe et al., 2014). In particular, understanding whether and how ecosystem services benefits to wellbeing differ among different social subgroups remains nascent (Daw et al., 2011). Populations, communities, and societies are socially diverse - i.e. made up of different groups, with varying identities, values, and experiences. This diversity impacts who benefits from ecosystem services, and influences what is considered fair in ecosystem service distribution and governance (Berbés-Blázquez et al., 2016; Daw et al., 2011; Sikor and Baggio, 2014). Large-scale, aggregated ecosystem service studies - the norm in ecosystem services research (Wieland et al., 2016) are unlikely to reflect the values of poorer or more marginalized people (Brooks et al., 2014), or to capture differences across social groups (Daw et al., 2011). Management based on aggregated studies may have unintended consequences on poverty alleviation, leading to inequitable socio-economic impacts that may further marginalize certain groups' interests (Adams, 2014; Berbés-Blázquez et al., 2016; Daw et al., 2011).

To date, research on social differentiation and ecosystem services has been growing but limited. Most studies addressing social differentiation have been single case studies (Orenstein \& Groner 2014; Lakerveld et al. 2015, although see Sodhi et al. 2010). Studies have differentiated by: livelihood type (e.g. Brooks et al., 2014; Caceres et al., 2015); or beneficiary group (Milcu et al., 2015); rural vs urban residents (Orenstein and Groner, 2014); citizenship (Orenstein and Groner, 2014); socio-cultural groups (Lakerveld et al., 2015; Sagie et al., 2013); socio-economic status (Dawson and Martin, 2015; Sodhi et al., 2010); length of residency or location (Dawson and Martin, 2015; Sodhi et al., 2010); and socio-ethnic group (Dawson and Martin, 2015). Studies contrast perceptions of ecosystem services (Caceres et al., 2015; Orenstein and Groner, 2014; Sodhi et al., 2010), needs and benefits (Lakerveld et al., 2015; Milcu et al., 2015), and access (Lakerveld et al., 2015). 
Many of these studies have found that people both benefit from and perceive ecosystem services differently. For example, in a valuation of wetland ecosystem services in Asia, government officials and business owners (i.e. decision makers) estimated wetland fisheries to have very little overall monetary value. However, for the livelihoods of poor fishermen and women dependent on the wetland ecosystem services these fisheries benefits were crucial (Brooks et al., 2014). In Argentina, subsistence farmers perceived many cultural ecosystem services benefits from the land, while large farmers perceived none (Caceres et al., 2015). In addition, work investigating urban and rural residents of the Arajun valley in Jordan and Israel has shown that political border and residential characteristics can define perceptions of ecosystem services (Orenstein \& Groner, 2014).

Work on the social dimensions of ecosystem services has been predominantly in terrestrial systems. Marine and coral reef ecosystem services remain under-researched from a wellbeing and human dimensions perspective (Rivero and Villasante, 2016), and ecosystem services work on poverty alleviation more broadly has tended to focus on cultivated and forested land (Suich et al., 2015). In line with this trend, most studies addressing social differentiation and ecosystem services are in terrestrial systems (Although see Daw et al., 2011). To our knowledge work that disaggregates the relative importance of and priorities for ecosystem services by socio-economic characteristics within groups traditionally assumed to make-up specific stakeholder groups (Reed et al., 2009), remains rare in coastal and marine systems.

Previous studies in the western Indian Ocean have shown that certain socio-economic factors meditate the benefits people perceive from ecosystem services (Hicks et al. 2014). More specifically, social relationships and institutions shape who can access ecosystem service benefits. Hicks et al. (2015) also found a great deal of variability within the ecosystem services that fishers prioritized for improvement. Here, we extend this work to understand how, and whether, wealth, age, and level of formal schooling shape differences. Specifically, we ask whether disaggregating by subgroups might illuminate logical stakeholder groups across scales, and whether we could identify the sorts of socio-economic characteristics that may shape variation in fishers' ecosystem services priorities. This study thus extends and deepens work on the role of socio-economic characteristics in shaping variability across ecosystem services priorities and importance.

We hypothesize that those who draw their livelihoods from coral reef fisheries directly (i.e. fishers, fish workers, and fish traders) may hold different priorities for ecosystem services depending on other socio-economic aspects of their identities. While often taken as an homogeneous stakeholder group, fisherfolk have diverse perspectives and experiences (Béné, 2003; Eder, 2005). Here, we explore whether disaggregating the importance of and priorities for coral reef ecosystem services is a useful avenue for understanding fisherfolks' similarity beyond solely fishery-related provisioning services. More specifically, we examined how fishers' socioeconomic characteristics (including age, years of formal schooling, and material wealth) are related to: i) the relative importance they place on ecosystem services; and ii) their priorities for improvement in the quality and/or quantity of ecosystem services across 28 communities in four countries in the western Indian Ocean.

\subsection{Background and Study Sites}


Countries in the western Indian Ocean are heavily reliant on marine and coastal ecosystem services. The region has a history of cultures and livelihoods based around fishing, maritime trade, and marine resource use, and a vision of 'people prospering from a healthy Western Indian Ocean' underpins key regional policies aimed at sustainable development (Obdura et al., 2017, p. 5). More specifically, coral reef fisheries are extremely important to many coastal communities throughout the region (Cinner and Bodin, 2010), but are highly vulnerable to global environmental change (Cinner et al., 2012). Coastal communities across the western Indian Ocean lack many of the resources necessary to adapt to losses of key coral reef ecosystem services. Our study draws on interviews conducted in 28 communities western Indian Ocean, from Kenya, Madagascar, Seychelles, and Tanzania. These communities were broadly representative of the region's rural fishing communities. Each face similar challenges of environmental stressors and lack of resources, and represent different types of reef management.

\section{Methods}

\subsection{Sampling}

This study is drawn from data gathered as part of a larger project on coral reef ecosystem services in the western Indian Ocean (Hicks et al., 2015; Hicks and Cinner, 2014). We surveyed a total of 372 fishers, fish workers, and fish traders (hereafter referred to collectively as fishers) from 28 coastal communities across Madagascar, Tanzania, Kenya, and the Seychelles. Respondents were randomly selected across gear types, residence, and age from fishers, fish traders, and fish factory workers registered with local fisher organizations or the fisheries department (i.e. a stratified random sampling approach). The communities were broadly representative of the region's rural fishing communities. We interviewed between 7 and 32 fishers per community, which represents $20-40 \%$ of all fishers. Respondents were mostly men, although we interviewed some women working as fish traders in Madagascar.

\subsection{Coral Reef Ecosystem Services}

To identify coral reef ecosystem service benefits in the western Indian Ocean, we held five focus groups with managers and scientists. We use the definition of ecosystem services as 'the functions and processes of ecosystems that benefit humans, directly or indirectly'(Costanza et al., 2017). From these discussions, we wrote short descriptions (Table 1) and selected photographs to represent each ecosystem service visually. We then refined and crosschecked the list, descriptions, and photographs with fishers in 30 focus groups across the four countries. The resulting nine ecosystem services were fishery, materials, education, bequest, culture, recreation, habitat, coastal protection, and sanitation (Table 1). The descriptions of these ecosystem service benefits were kept broad to fit with different cultural contexts. 


\begin{tabular}{|c|c|}
\hline Coastal protection & The benefit we gain from having the reef buffer the force of the waves. \\
\hline Sanitation & $\begin{array}{l}\text { The benefit we gain from using the sea to wash and clean, knowing that when we come } \\
\text { back tomorrow the waters will be clear again. }\end{array}$ \\
\hline Recreation & $\begin{array}{l}\text { The benefits we gain from being able to relax and enjoy the } \\
\text { marine environment or having others come and enjoy it in this way. }\end{array}$ \\
\hline Bequest & $\begin{array}{l}\text { The benefits we gain from knowing we will have healthy reefs that we can pass on to } \\
\text { our children so that they can benefit from all the benefits that we do today. }\end{array}$ \\
\hline Education & $\begin{array}{l}\text { The benefits we gain from the knowledge we have from the time we and our elders } \\
\text { have spent in the marine environment. }\end{array}$ \\
\hline Cultural & The benefits we gain from having cultural connections to the marine environment. \\
\hline
\end{tabular}

199 Our study measured i) the relative importance of an ecosystem service to people's

200 lives and ii) people's priorities for improving the quality or quantity of different

201 services. To calculate the relative importance, we asked respondents to rank the nine 202 ecosystem services in order of importance to their lives (Hicks et al., 2015). To elicit

203 the priorities for improvement in ecosystem services, we asked respondents to

204 distribute 20 counters across the ecosystem services, based on where they would most

205 like to see an improvement in quality or quantity. Examples of improvement may 206 include a healthier reef (habitat), more productive fishing trips (fishery), or better 207 coastal protection (coastal protection). After pilot testing this approach, we found that 208 respondents put more thought into their distribution when working with fewer

209 counters. Therefore, we provided respondents with only five counter at a time. Once a 210 respondent had laid down their first five counters, we then provided them with the 211 next five, and repeated this until they had distributed all 20 counters. We then 212 weighted each round, to reflect that the first five matches held more weight than 213 successive rounds (see Hicks et al., 2015). These weighted scores were then 214 normalized to create continuous data that reflected an estimate of priorities for 215 ecosystem services' improvement.

\subsection{Socio-economic characteristics}

We examined four socio-economic characteristics including two indicators of wealth, years of formal schooling, and age. We measured relative wealth (Pollnac and Crawford., 2000) based on the presence of household items and facilities (such as a mobile phone, electricity); the types of household structures (e.g. materials used for flooring, walls, and roofs) and fortnightly expenditure. We used a principle component analysis with varimax rotation to incorporated these variables into one wealth indicator explaining 59\% of variance (see Table 3 in supplementary material). This indicator is hereafter referred to as relative wealth. We calculated the second wealth indicator (fisheries asset wealth) based respondent's investment in fishing gear on a scale of 1 to 4 , with 1 being the lowest, and 4 the highest. Fishers were given a score according to whether they owned the following types of gear (ordered from least expensive to most expensive); spear gun, line, trap, and net (see Table 3 in supplementary material). We used these two wealth indicators because one represents a more general material style of life measurement, while the other is related to direct investment in reef fisheries. We hypothesized that groups within each of the two wealth indicators might differ in the rating and ranking because the indicators are not correlated. We also asked respondents' age (in years), and years of formal schooling. 
We then calculated the quartiles of each socio-economic characteristic (Table 2) and used each quartile as a categorical variable in our analysis.

\begin{tabular}{|c|c|c|c|c|}
\hline Socio-economic indicators & Q1 & Q2 & Q3 & Q4 \\
\hline Age (years) & $<29$ & $29-37$ & $37-46$ & $>46$ \\
\hline Education (years) & $<4$ & $4-7$ & $7-8$ & $>8$ \\
\hline
\end{tabular}

Table 2. Years of age and formal education binned as quartiles. $\mathrm{Q} 1=1^{\text {st }}$ quartile. $\mathrm{N}=93$ per quartile.

\subsection{Analysis}

We used ordinal mixed effects regression models for each of the nine ecosystem services to test whether differences existed between quartiles for the relative importance of ecosystem services (ranked). For each model, a priori we specified country and community as random effects to account for the nested structure of the data (i.e. individuals nested in community, nested in country). We also identified and removed variables that failed the proportional odds assumptions, and re-fit models without them. We then used the Akaike information criteria values (AIC) to select the best model fit, and chose the most parsimonious model in each case. We compared this model with a null model with country and community specified as random effects. In the cases where the null model was the best fit we discontinued analysis. For the remaining models, we identified significant relationships and conducted posthoc tests using least-squares means comparisons for multiple groups with Tukey contrasts between quartiles.

To analyse the priorities for improvement in ecosystem services, we fit a series of linear mixed effects models (LMMs). Again, we fit models with community and country specified as a priori random effects, and then dropped variables to determine the most parsimonious model. None of the variables suffered from multi-collinearity, the variance inflation factors were less than 5 in each model (supplementary material). As above, where the null model proved as good or a better fit, we discontinued analysis. For the remaining models, we identified predictor variables with significant effects and conducted multiple comparisons of means post-hoc tests using Tukey contrasts between quartiles. For each LMM model we checked for assumptions of normality and homogeneity.

\section{Results}

Overall, we found few significant differences between how social subgroups rank the relative importance of and prioritize improvements in ecosystem services in the western Indian Ocean (Fig. 1, Table 3, Table 4). As expected, our 372 reef-dependant respondents generally ranked fishery benefits as both important and a high priority for improvement. Knowledge benefits and habitat benefits were also ranked highly, and prioritized for improvement overall. The differences we did find mostly fell across these three highly ranked and highly prioritized ecosystem services, and were between relative wealth and age groups. There were no significant differences between how people with different levels of formal education ranked and rated ecosystem services. In addition, the only difference between fisheries asset wealth groups was that the wealthy group (Q3) prioritised improving recreational benefits more than the poorest group $(\mathrm{Q} 1, \mathrm{p}=0.007)$. 
a)

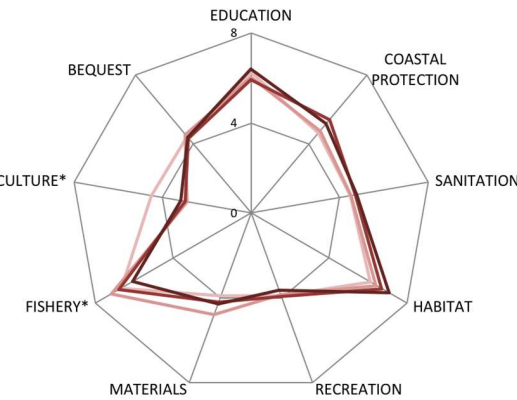

c)

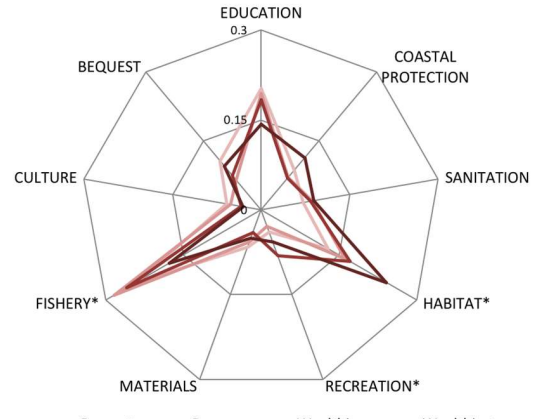

b)

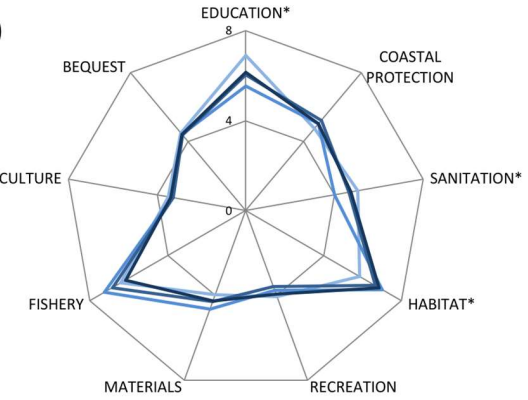

d)

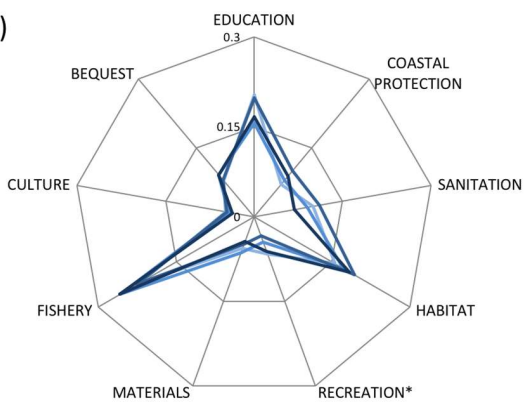

Figure 1. Mean ranked relative importance of ecosystem services for groups in the western Indian Ocean (a score of 9 indicates the highest rank), with a) relative wealth quartiles and b) age quartiles. Mean priorities for improvement in ecosystem services for groups with c) relative wealth quartiles and d) age quartiles. Significant differences between groups are denoted $*$. Note that years of formal schooling and fisheries asset wealth are not depicted here because they have no or very few significant differences.

\subsection{Wealth}

Most of the differences in rankings and ratings of ecosystem services fell across relative wealth groups. We found that fishers in the poor group (Q2) ranked fishery benefits higher than those in the wealthiest group (Q4), and this was also the case for their priorities for improvement (Fig. 1, Table 2). Coral reef habitat provides shelter and food for fish, and is therefore a key supporting ecosystem service for reef fisheries. We found that fishers consistently ranked habitat benefits as highly important, but that desire to improve habitat functions may be influenced by relative levels of wealth. The wealthiest fishers (Q4) prioritized improvements in habitat benefits more than all other fishers (Error! Reference source not found.,

\begin{tabular}{|c|c|c|c|c|}
\multirow{2}{*}{ Relative Importance (rank) } & \multirow{2}{*}{ Ecosystem Service } & \multicolumn{3}{|c|}{ Differences between quartiles } \\
\cline { 3 - 5 } & & $\underline{\text { Higher }}$ & $\underline{\text { Lower }}$ & $\underline{\mathrm{P} \text { value }}$ \\
\cline { 3 - 5 } & $\underline{\text { Culture }}$ & $\underline{\mathrm{Q} 2}$ & $\underline{\mathrm{Q} 4}$ & $\underline{0.001}$ \\
\hline & $\underline{\text { Fishery }}$ & $\underline{\mathrm{Q} 2}$ & $\underline{\mathrm{Q} 2}$ & $\underline{0.016}$ \\
\hline
\end{tabular}




\begin{tabular}{|c|c|c|c|c|}
\hline \multirow{4}{*}{$\frac{\text { Priority for Improvement }}{\text { (rate) }}$} & \multirow{3}{*}{ Habitat } & $\underline{\mathrm{Q}} 4$ & $\underline{\mathrm{Q} 1}$ & $<0.001$ \\
\hline & & $\underline{\mathrm{Q}} 4$ & $\underline{\mathrm{Q}}$ & $\underline{0.009}$ \\
\hline & & Q4 & Q3 & 0.024 \\
\hline & Recreation & $\underline{\mathrm{Q} 3}$ & $\underline{\mathrm{Q} 2}$ & $\underline{0.028}$ \\
\hline
\end{tabular}

\section{$\underline{\text { Table } 3}$}

).

We also found several differences between how different wealth groups ranked cultural ecosystem services; recreation, and culture. The poorest fishers (Q1) ranked cultural benefits as more important than those slightly wealthier fishers in the poor group (Q2). In contrast, wealthier fishers prioritized an improvement in recreational benefits. We defined recreational services as 'the benefits we gain from being able to relax and enjoy the marine environment or having others come and enjoy it in this way'. Thus, recreation benefits include enjoying the reef oneself, or drawing one's livelihood from others' recreation, e.g. through tourism. The wealthy group (Q3) prioritized an improvement in recreational benefits more than the poor group (Q2).

\begin{tabular}{|c|c|c|c|c|}
\hline \multirow{2}{*}{ Relative Importance (rank) } & \multirow{2}{*}{ Ecosystem Service } & \multicolumn{3}{|c|}{ Differences between quartiles } \\
\cline { 2 - 5 } & Fishery & Higher & Lower & P value \\
\cline { 2 - 5 } & Culture & Q1 & Q4 & 0.001 \\
\hline \multirow{4}{*}{$\begin{array}{c}\text { Priority for Improvement } \\
\text { (rate) }\end{array}$} & Fishery & Q2 & Q4 & 0.016 \\
\cline { 2 - 5 } & \multirow{3}{*}{ Habitat } & Q4 & Q1 & $<0.024$ \\
\cline { 2 - 5 } & & Q4 & Q2 & 0.001 \\
\cline { 2 - 5 } & Recreation & Q4 & Q3 & 0.024 \\
\hline
\end{tabular}

Table 3. Differences between ranking and rating of ecosystem services between wealth groups based on material style of life scores for household items. Legend. Q1: poorest; Q2: poor; Q3: wealthy; Q4: wealthiest.

\subsection{Age}

As with wealth, there were few differences between age and people's ranking and rating of ecosystem services. Overall, fishers of all ages overwhelmingly ranked fishery benefits as most important, and as a key priority for improvement. Of the few differences across age groups, most fell between those in the younger groups, rather than young fishers and old fishers (Figure 1 Table 4). The fishers under 29 years old (Q1) considered education benefits more important and habitat benefits less important compared to those slightly older, between 29 and 37 years old (Q2). Fishers under 29 years old (Q1) also prioritized improvement in education benefits more than the fishers between 29 and 37 (Q2) years old, and prioritized improvement in recreational benefits more than fisher between 37 and 49 (Q3) (Table 4). We found no significant differences in the relative importance of education and habitat services between the youngest and oldest groups. On no occasion were the relative importance of ecosystem services nor priorities for improvement within the oldest group (above 49, Q4) significantly different from other age groups. 


\begin{tabular}{|l|c|c|c|c|}
\multirow{3}{*}{ Relative Importance (rank) } & Education & Q1 & Q2 & 0.0061 \\
\cline { 2 - 5 } & Habitat & Q2 & Q1 & 0.0154 \\
\cline { 2 - 5 } & Sanitation & Q1 & Q2 & 0.0015 \\
\hline Priority for Improvement (rate) & Recreation & Q1 & Q3 & 0.0359 \\
\hline
\end{tabular}

Table 4. Differences between ranking and rating of ecosystem services between age groups. Legend: Q1:<29; Q2: 29-37; Q3: 37-49; Q4: >49.

\section{Discussion}

Approaching conservation and resource management equitably is not only morally imperative, but also crucial for conservation or management success. Equitable environmental management requires decision-makers to identify and navigate tradeoffs between the priorities of different social groups or stakeholders (McShane et al., 2011; Reyers et al., 2009). Thus, identifying how different people value and prioritize ecosystem services is a crucial step for equitable and successful ecosystem servicebased approaches (Daw et al., 2015; Sikor et al., 2014). However, much conservation practice and ecosystem services research presumes that stakeholder groups are homogenous, easily recognizable and simply need to be categorized (Leach et al., 1997; Reed, 2008). In fisheries, non-major stakeholders' interests are often left out altogether (Degnbol et al., 2006). We focused solely on priorities of fishers, and those with fisheries related livelihoods, to better understand social differentiation. While we hypothesized that there would be differences between how fishers with different socio-economic characteristics ranked and rated ecosystem services, we found, instead, many similarities in what ecosystem services are important and prioritised. We found only 12 significant differences across fishers in the western Indian Ocean region. The three ecosystem services most consistently highly ranked and prioritized fall across three ecosystem service categories: provisioning (fishery), supporting (habitat), and education (culture). This finding suggests that fishers in general do recognize and prioritize both direct and indirect ecosystem services. We begin by exploring these similarities and their implications, before turning to the differences we did find between socio-economic subgroups, and finally turn to key considerations for future work in ecosystem services.

\subsection{Similarities in ranking and rating}

Our results emphasize that there are many similarities in the way fishers across the region rank and prioritize ecosystem services. There are several possible reasons for these similarities. Firstly, fishers across the western Indian Ocean likely interact with coral reef ecosystem services regularly and in a similar way. Our respondents are broadly representative of the regions' rural coastal communities, and all engage with coral reef fisheries as a key livelihood. The way fishers interact with ecosystem services is also likely different to other stakeholders, for instance, tourist operators or small-business owners. However, we were unable to capture some key dimensions of the social difference within the fisher group that may have highlighted more differences. We identified socio-economic characteristics a priori, and therefore our findings could not capture potential differences across, for instance, gender and ethnicity. Gender, for instance, shapes ecosystem services preferences (Villamor and van Noordwijk, 2016) but because our respondents were mostly male we could not disaggregate by gender. Secondly, our ecosystem services themselves were
Commented [GG1]: This para is looking really great with those small edits =) 
necessarily broad to make analysis comparable across the region. At a local casestudy level, preference and perceptions of ecosystem services are complex and can differ down to the minutiae of species (Díaz et al., 2011). While our more general ecosystem services were necessary for examining an entire region, were established using a range of participatory methods, and were tailored to each context, this broadness may have obscured differences across, for instance, species.

The broad similarities in ranking and rating of ecosystem services that we identified can provide insights for decision-makers. For instance, our findings emphasize knowledge is a uniformly highly-valued cultural ecosystem service among fishers of different wealth groups and ages in the western Indian Ocean. The importance fishers place on environmental knowledge may reflect a strong sense of social identity often documented in small-scale fisheries, which is a crucial aspect of subjective wellbeing (Britton and Coulthard, 2013; Coulthard et al., 2011). We found no differences between years of formal education, and the perceived value of ecological knowledge. Fishers who had completed more years of formal schooling did not value or prioritize the benefits of experiential and inherited ecological knowledge differently than those with little or no formal education. This re-emphasizes work that suggests that ecological knowledge is fostered more through experience than through formal education (Reyers et al., 2009). Our findings therefore add weight to calls to better integrate local and traditional environmental knowledge into fisheries management broadly (Hind, 2015; Johannes et al., 2000), and in the western Indian Ocean specifically (Gaspare et al., 2015; e.g. Katikiro et al., 2015; Moshy and Bryceson, 2016).

\subsection{Differences and the poverty-fishery nexus}

Our findings around poverty and ecosystem services both challenge and support dominant narratives around poverty and fisheries. Overfishing and environmental degradation in fisheries has historically been framed in Malthusian terms of selfinterested individuals with concern only for the instrumental values of fisheries and a desire for increasing production at the cost of sustainability (Finkbeiner et al. 2017). In addition, studies of fisheries and poverty have tended to conflate poverty with lack of income (Bene et al. 2011), and assume that small-scale fishers are trapped in an inescapable poverty cycle (Bene et al. 2003). Our findings speak directly to these narratives because the fishers in our sample are relatively poor compared to those with different livelihoods in the region. Indeed, Cinner (2010) found that in Kenya fishers had a lower overall level of wealth, in terms of asset accumulation, than nonfishers.

Our study adds weight to evidence challenging the Malthusian framing of fishers and overfishing. Specifically, we found that all fishers in our sample, regardless of relative wealth, do perceive in-direct benefits from habitat function and ecological knowledge to be important to their lives. And, importantly, the relatively wealthier individuals in our sample prioritized the need to improve habitat function. Therefore, on one hand, our results broadly challenge the notion that all small-scale fishers are trapped in cycles of poverty causing overexploitation (Bene et al. 2003) and cannot or do not prioritize sustainability. However on the other hand, our results suggest that poverty does make a difference to the ecosystem services that fishers prioritize improvements in. 
Despite uniformity in what is considered important by fishers, the poorest do not or cannot prioritize improvement in habitat services (Martinez-Alier, 2014). Large-scale analysis of environmental concern has suggested that environmental care is a 'luxury', based on post-materialist values only held by the well-off (Dunlap and York, 2008). Our findings reflect and support the argument that the ability to prioritize enhancing in-direct benefits from the environment, may be a luxury. Greater affluence within a fisheries livelihood may play a role in whether people prioritize improving habitat services. In Kenya and Tanzania, Cinner (2010) found that, when faced with a declining fishery, poorer fishers were much more likely to use destructive fishing gears that could damage sensitive marine habitats. This link between wealth and priorities around improving habitat matter for management because when people do not hold priorities for improvement (i.e. where their rating is low), they are unlikely to engage in management actions targeting these ecosystem services. This may be because they are unable to, or are, in fact, unconcerned, which may be broadly linked to levels of awareness, knowledge, and apathy.

The only differences in ecosystem services preferences we found in terms of age, were rankings of education, sanitation, and habitat ecosystem services, and in priorities for improving recreational services. This is a surprising result because rather than a stark gap between the values and priorities of the oldest versus the youngest fishers, the most differences were between the two younger groups (i.e. those younger than 29, and those between 29 and 37). At face value, this finding suggests that incorporating younger fishers' interests around ecosystems services into decisionmaking will be straightforward because their priorities align with those of older fishers who tend to be in greater positions of power and have greater legitimacy in decision-making (Colfer, 2011). Nonetheless, it is possible that rather than the importance of and priorities for changing ecosystems services, differences in opinion, and hence conflicts about fisheries and coral reef governance between older and younger generations may occur across aspects we did not capture, such as changing cultural identities across generations (Zurba and Trimble, 2014).

Finally, we found wealthier fishers did prioritize an improvement in recreational benefits slightly more than poor fishers. This result likely reflects that wealthier fishers have more flexibility, an openness to change, and perhaps the desire to engage in alternative livelihoods such as tourism (Hicks et al., 2015). More broadly, however, the relatively low priorities that fishers gave to recreational ecosystem services suggests that they are either unable to benefit much from the industry or do not desire to participate in it. The ability to engage with and benefit from the tourism industry likely requires certain skill sets that local fishers do not have. Our results highlight the relative disconnect between fishers and fish traders, and the tourism industry. Improving recreational ecosystem service benefits is therefore unlikely to alleviate poverty in the poorest fishers in the short term, as they are likely unable, or perhaps lack the desire to, engage with the tourism industry. Our analysis is therefore able to illuminate where alternative livelihoods may be inappropriate for various reasons. Tourism, based on recreational ecosystem services, is a key industry in the western Indian Ocean. Yet, tourism, as a strategy for reducing environmental vulnerability through economic development, may not only have negative social impacts (Diedrich and Aswani, 2016), but may actually not be accessible or desired by fishers highly vulnerable to environmental change. It is striking that recreational benefits were not 
valued or prioritized more by fishers, given the importance of tourism in the region. In the western Indian Ocean, coastal tourism generates around US\$10.4 billion annually, almost 10 times the revenue from the entire fishery and aquaculture sector (Obdura et al., 2017).

\subsection{Implications and future work}

Disaggregating ecosystem services across social sub-groups within fishers in the western Indian Ocean can extend and deepen debates around the nexus between poverty and small-scale fisheries. Specifically, separating the ranking and rating exercise can highlight what is important, and where change is actively wanted. For instance, in this case, fishery is consistently highly important and highly prioritized, whereas habitat is consistently highly important but only the wealthiest actively prioritize its improvement. Alongside perceptions of the costs and benefits of conservation strategies to people's livelihoods (Bennett, 2016; Gurney et al., 2014), socially differentiated data on ecosystem services can provide evidence for designing appropriate conservation and management strategies but also, crucially, framing these strategies to different socio-economic groups. For example, in the western Indian Ocean, ecosystem-based conservation and management targeting habitat and ecosystem function (Pikitch et al., 2004) may resonate more with wealthier fishers.

Future work should include important socio-economic characteristics including gender, ethnicity, and class. Understanding differences at a local level will likely require concurrent qualitative methods to undercover why people hold priorities, how these priorities intersect with their resource needs, and how access in different contexts (Fisher et al., 2015; Daw et al., 2017). Our study emphasizes the need for continued re-engagement with methods for selecting and understanding stakeholders and their priorities. Rather than assuming, for instance, that all small-scale fishers are stuck in poverty traps, our findings re-affirmed that there are different levels of wealth within fisheries, and that this difference is reflected in the priorities people have for improving habitat function.

Disaggregating the social dimensions of ecosystem services is just one aspect of making ecosystem service based research and management more equitable. Tackling and understanding issues of elite capture and power (see Blaikie, 2006) in ecosystem service based approaches (e.g. payments for ecosystem services) will require deeper engagement with the justices and injustices of ecosystem services in specific contexts (Jax et al., 2013; Sikor, 2013). A key step towards justice is highlighting diverse priorities, plural perceptions, and worldviews around ecosystem services so that decisions-makers might make more environmentally-just decisions (Diaz et al. 2016). This attention to social differentiation is likewise crucial in fisheries, where political disempowerment is a key aspect of poverty and marginalization (Béné, 2003). Identifying what ecosystem services are important and where people desire an improvement is key to equitable policy and decision-making around poverty alleviation and conservation (Campbell et al., 2010).

\section{Conclusion}

Commented [GG6]: Note the differences in the way the with a ., 
530 As key global ecosystem services are lost, environmental management has a moral

531 and environmental imperative to embrace and include multiple perspectives (Adams,

532 2016). Investigating how socio-economic groups value and prioritize ecosystem

533 services differently is a key step towards understanding what matters to whom and to

534 interrogating dominant narratives around the fisheries and poverty. Assessing and

535 disaggregating both the importance of ecosystem services, but also priorities for

536 improvement is a useful tool for gaining a broader sense of what different and diverse

537 fishers (or another stakeholder group) might want and what they may have in

538 common. For instance, in the western Indian Ocean, ecosystem-based management

539 that emphasizes protecting habitat may resonate more with certain groups, in this case

540 wealthier fishers, whereas poorer fishers might be more inclined to support strategies

541 aimed at increasing fisheries benefits. Our work concurrently supports the idea that

542 poorer fishers may be unable to prioritize in-direct ecosystem services, but highlights

543 that this is not because they do not perceive these services to be important. Ecosystem

544 service based research needs to look beyond simplistic understandings of difference,

545 and to interrogate pre-defined stakeholder groups to move towards social and

546 environmental justice.

Commented [GG8]: Nice conclusion $=$ ) 


\section{Acknowledgements}

Many thanks to C. Abunge, R. Charo, D. Julie, and R. Solovo for assistance in the field, and to the many fishers for their time and knowledge. Thank-you to the Wildlife Conservation Society (WCS) Madagascar and the Seychelles Fishing Authority who provided logistical support. We also thank three anonymous reviewers for their helpful comments, which greatly improved the manuscript.

\section{Funding}

This work was supported by the the Western Indian Ocean Marine Science Association (WIOMSA) through the Marine Science for Management scheme (MASMA). All authors acknowledge support from the Australian Research Council Centre of Excellence for Coral Reef Studies. C. Hicks acknowledges support from the Lancaster Environment Centre.

\section{References}

Adams, W.M., 2016. Do you speak Lion? Science (80-. ). 17, 626-629. doi:10.1126/science.aaf8056

Adams, W.M., 2014. The value of valuing nature. Science (80-. ). 346, 549-552.

Béné, C., 2003. When Fishery Rhymes with Poverty: A First Step Beyond the Old Paradigm on Poverty in Small-Scale Fisheries. World Dev. 31, 949-975. doi:http://dx.doi.org/10.1016/S0305-750X(03)00045-7

Bennett, N.J., 2016. Use of perceptions to improve conservation and environmental management. Conserv. Biol. 0, 1-5. doi:10.1007/s13398-014-0173-7.2

Berbés-Blázquez, M., González, J.A., Pascual, U., 2016. Towards an ecosystem services approach that addresses social power relations. Curr. Opin. Environ. Sustain. 19, 134-143. doi:10.1016/j.cosust.2016.02.003

Blaikie, P., 2006. Is Small Really Beautiful? Community-based Natural Resource Management in Malawi and Botswana. World Dev. 34, 1942-1957. doi:http://dx.doi.org/10.1016/j.worlddev.2005.11.023

Britton, E., Coulthard, S., 2013. Assessing the social wellbeing of Northern Ireland's fishing society using a three-dimensional approach. Mar. Policy 37, 28-36. doi:10.1016/j.marpol.2012.04.011

Brooks, E.G.E., Smith, K.G., Holland, R.A., Poppy, G.M., Eigenbrod, F., 2014. Effects of methodology and stakeholder disaggregation on ecosystem service valuation. Ecol. Soc. 19.

Caceres, D.M., Tapella, E., Quetier, F., Diaz, S., 2015. The social value of biodiversity and ecosystem services from the perspectives of different social actors. Ecol. Soc. 20. doi:10.5751/ES-07297-200162 
Campbell, B.M., Sayer, J.A., Walker, B., 2010. Navigating trade-offs: Working for conservation and development outcomes. Ecol. Soc. 15, 2. doi:16

Cinner, J., McClanahan, T., Graham, N., Daw, T., Maina, J., Stead, S.M.M., Wamukota, A., Brown, K., Bodin, Ö., 2012. Vulnerability of coastal communities to key impacts of climate change on coral reef fisheries. Glob. Environ. Chang. 22, 12-20. doi:10.1016/j.gloenvcha.2011.09.018

Cinner, J.E., 2010. Poverty and the use of destructive fishing gear near east African marine protected areas. Environ. Conserv. 36, 321-326. doi:10.1017/S0376892910000123

Cinner, J.E., Bodin, Ö., 2010. Livelihood diversification in tropical coastal communities: A network-based approach to analyzing "livelihood landscapes." PLoS One 5. doi:10.1371/journal.pone.0011999

Cinner, J.E., McClanahan, T.R., Wamukota, A., 2010. Differences in livelihoods, socioeconomic characteristics, and knowledge about the sea between fishers and non-fishers living near and far from marine parks on the Kenyan coast. Mar. Policy 34, 22-28. doi:10.1016/j.marpol.2009.04.003

Colfer, C.J.P., 2011. Marginalized forest peoples' perceptions of the legitimacy of governance: An exploration. World Dev. 39, 2147-2164. doi:10.1016/j.worlddev.2011.04.012

Costanza, R., Arge, R., Groot, R. De, Farberk, S., Grasso, M., Hannon, B., Limburg, K., Naeem, S., O’Neill, R. V, Paruelo, J., Raskin, R.G., Suttonkk, P., van den Belt, M., 1997. The value of the world's ecosystem services and natural capital. Nature 387, 253-260. doi:10.1038/387253a0

Costanza, R., de Groot, R., Braat, L., Kubiszewski, I., Fioramonti, L., Sutton, P., Farber, S., Grasso, M., 2017. Twenty years of ecosystem services: How far have we come and how far do we still need to go? Ecosyst. Serv. 28, 1-16. doi:10.1016/j.ecoser.2017.09.008

Coulthard, S., Johnson, D., McGregor, J., 2011. Poverty, Sustainability and Human Wellbeing: A social wellbeing approach to the global fisheries crisis. Glob. Environ. Chang. 453-463.

Daily, G., 1997. Nature's Services: Societal Dependence On Natural Ecosystems. Island Press, Washington.

Daw, T., Brown, K., Rosendo, S., Pomeroy, R., 2011. Applying the ecosystem services concept to poverty alleviation: the need to disaggregate human wellbeing. Environ. Conserv. 34, 370-379.

Daw, T.M., Coulthard, S., Cheung, W.W.L., Brown, K., Abunge, C., Galafassi, D., Peterson, G.D., McClanahan, T.R., Omukoto, J.O., Munyi, L., 2015. Evaluating taboo trade-offs in ecosystems services and human well-being. Proc. Natl. Acad. Sci. 201414900. doi:10.1073/pnas.1414900112

Dawson, N., Martin, A., 2015. Assessing the contribution of ecosystem services to human wellbeing: A disaggregated study in western Rwanda. Ecol. Econ. 117, 62-72. doi:10.1016/j.ecolecon.2015.06.018

Degnbol, P., Gislason, H., Hanna, S., Jentoft, S., Raakjær Nielsen, J., SverdrupJensen, S., Clyde Wilson, D., 2006. Painting the floor with a hammer: Technical fixes in fisheries management. Mar. Policy 30, 534-543. doi:10.1016/j.marpol.2005.07.002

Díaz, S., Quétier, F., Cáceres, D.M., Trainor, S.F., Pérez-Harguindeguy, N., BretHarte, M.S., Finegan, B., Peña-Claros, M., Poorter, L., 2011. Linking functional diversity and social actor strategies in a framework for interdisciplinary analysis of nature's benefits to society. Proc. Natl. Acad. Sci. U. S. A. 108, 895-902. 
doi:10.1073/pnas.1017993108

Diedrich, A., Aswani, S., 2016. Exploring the potential impacts of tourism development on social and ecological change in the Solomon Islands. Ambio 45, 808-818. doi:10.1007/s13280-016-0781-x

Dunlap, R.E., York, R., 2008. The Globalization of Environmental Concern and the Limits of the Postmaterialist Values Explanation : Evidence from Four Multinational Surveys 49, 529-563. doi:10.1111/j.1533-8525.2008.00127.x

Eder, J.F., 2005. Coastal resource management and social differences in Philippine fishing communities. Hum. Ecol. 33, 147-169. doi:10.1007/s10745-005-2430-Z

Fish, R., Church, A., Winter, M., 2016. Conceptualising cultural ecosystem services: a novel framework for research and critical engagement. Ecosyst. Serv. 1-10. doi:10.1016/j.ecoser.2016.09.002

Fisher, J.A., Patenaude, G., Giri, K., Lewis, K., Meir, P., Pinho, P., Rounsevell, M., Williams, M., 2014. Understanding the relationships between ecosystem services and poverty alleviation: A conceptual framework. Ecosyst. Serv. 34-45.

Fisher, J. a., Patenaude, G., Meir, P., Nightingale, A.J., Rounsevell, M.D. a, Williams, M., Woodhouse, I.H., 2013. Strengthening conceptual foundations: Analysing frameworks for ecosystem services and poverty alleviation research. Glob. Environ. Chang. 23, 1098-1111. doi:10.1016/j.gloenvcha.2013.04.002

Gaspare, L., Bryceson, I., Kulindwa, K., 2015. Complementarity of fishers' traditional ecological knowledge and conventional science: Contributions to the management of groupers (Epinephelinae) fisheries around Mafia Island, Tanzania. Ocean Coast. Manag. 114, 88-101. doi:10.1016/j.ocecoaman.2015.06.011

Gómez-Baggethun, E., de Groot, R., Lomas, P.L., Montes, C., 2010. The history of ecosystem services in economic theory and practice: From early notions to markets and payment schemes. Ecol. Econ. 69, 1209-1218. doi:10.1016/j.ecolecon.2009.11.007

Gurney, G.G., Cinner, J., Ban, N.C., Pressey, R.L., Pollnac, R., Campbell, S.J., Tasidjawa, S., Setiawan, F., 2014. Poverty and protected areas: An evaluation of a marine integrated conservation and development project in Indonesia. Glob. Environ. Chang. 26, 98-107. doi:10.1016/j.gloenvcha.2014.04.003

Hicks, C.C., Cinner, J.E., 2014. Social, institutional, and knowledge mechanisms mediate diverse ecosystem service benefits from coral reefs. Proc. Natl. Acad. Sci. 111, 17791-17796. doi:10.1073/pnas.1413473111

Hicks, C.C., Cinner, J.E., Stoeckl, N., McClanahan, T.R., 2015. Linking ecosystem services and human-values theory. Conserv. Biol. 29, 1471-1480. doi:10.1111/cobi. 12550

Hind, E.J., 2015. A review of the past, the present, and the future of fishers' knowledge research: a challenge to established fisheries science. ICES J. Mar. Sci. 72, 341-358. doi:10.1093/icesjms/fsu169

Howe, C., Suich, H., Vira, B., Mace, G., 2014. Creating win-wins from trade-offs? Ecosystem services for human well-being: A meta-analysis of ecosystem service trade-offs and synergies in the real world. Glob. Environ. Chang. 28, 263-275. doi:10.1016/j.gloenvcha.2014.07.005

Jax, K., Barton, D.N., Chan, K.M.A., de Groot, R., Doyle, U., Eser, U., Görg, C., Gómez-Baggethun, E., Griewald, Y., Haber, W., Haines-Young, R., Heink, U., Jahn, T., Joosten, H., Kerschbaumer, L., Korn, H., Luck, G.W., Matzdorf, B., Muraca, B., Neßhöver, C., Norton, B., Ott, K., Potschin, M., Rauschmayer, F., von Haaren, C., Wichmann, S., 2013. Ecosystem services and ethics. Ecol. Econ. 
93, 260-268. doi:10.1016/j.ecolecon.2013.06.008

Johannes, R.E., Freeman, M.M.R., Hamilton, R.J., 2000. Ignore fishers' knowledge and miss the boat. Fish Fish. 1, 257-271. doi:10.1111/j.1467-2979.2000.00019.x

Katikiro, R., Ashoka Deepananda, K.H.M., Macusi, E., 2015. Interplay between perceived changes in fishery and social structures in Tanzanian coastal fishing communities. Fish. Res. 164, 249-253. doi:10.1016/j.fishres.2014.12.009

Lakerveld, R.P., Lele, S., Crane, T.A., Fortuin, K.P.J., Springate-Baginski, O., 2015. The social distribution of provisioning forest ecosystem services: Evidence and insights from Odisha, India. Ecosyst. Serv. 14, 56-66. doi:10.1016/j.ecoser.2015.04.001

Leach, M., Mearns, R., Scoones, I., 1997. Environmental entitlements: a framework for understanding the institutional dynamics of environmental change. IDS Discuss. Pap. 359, 1-39.

MA (Millenium Ecosystem Assessment), 2005. Ecosystems and human well-being: synthesis. Island Press, Washington, D.C.

Martinez-Alier, J., 2014. The environmentalism of the poor. Geoforum 54, 239-241. doi:10.1016/j.geoforum.2013.04.019

McShane, T.O., Hirsch, P.D., Trung, T.C., Songorwa, A.N., Kinzig, A., Monteferri, B., Mutekanga, D., Thang, H. Van, Dammert, J.L., Pulgar-Vidal, M., WelchDevine, M., Peter Brosius, J., Coppolillo, P., O’Connor, S., 2011. Hard choices: Making trade-offs between biodiversity conservation and human well-being. Biol. Conserv. 144, 966-972. doi:10.1016/j.biocon.2010.04.038

Milcu, A.I., Leventon, J., Hanspach, J., Fischer, J., 2015. Disaggregated contributions of ecosystem services to human well-being in low-intensity farmland. Reg. Environ. Chang. 117-163. doi:10.1007/s10113-016-0926-2

Moshy, V.H., Bryceson, I., 2016. Seeing Through Fishers' Lenses. SAGE Open 6, 215824401664171. doi:10.1177/2158244016641716

Obdura, D., Smits, M., Chaudhry, T., McPhillips, J., Beal, D., Astier, C., Gamblin, P., Tanzer, J., Burgener, V., Owen, S., Gonzales, A., 2017. Reviving the Western Indian Ocean Economy: Actions for a Sustainable Future. WWF International, Gland, Switzerland.

Orenstein, D.E., Groner, E., 2014. In the eye of the stakeholder: Changes in perceptions of ecosystem services across an international border. Ecosyst. Serv. 8, 185-196. doi:10.1016/j.ecoser.2014.04.004

Pikitch, E.K., Santora, C., Babcock, E.A., Bakun, A., Bonfil, R., Conover, D.O., Dayton, P., Doukakis, P., Fluharty, D., Heneman, B., Houde, E.D., Link, J., 2004. Ecosystem-Based Fishery Management. Science (80-. ). 305, 346-347.

Pollnac, R., Crawford., B., 2000. Assessing behavioural aspects of coastal resource use. Narragansett, RI.

Reed, M.S., 2008. Stakeholder participation for environmental management: A literature review. Biol. Conserv. 141, 2417-2431. doi:10.1016/j.biocon.2008.07.014

Reed, M.S., Graves, A., Dandy, N., Posthumus, H., Hubacek, K., Morris, J., Prell, C., Quinn, C.H., Stringer, L.C., 2009. Who's in and why? A typology of stakeholder analysis methods for natural resource management. J. Environ. Manage. 90, 1933-1949. doi:10.1016/j.jenvman.2009.01.001

Reyers, B., O'Farrell, P.J., Cowling, R.M., Egoh, B.N., le Maitre, D.C., Vlok, J.H.J., 2009. Ecosystem services, land-cover change, and stakeholders: Finding a sustainable foothold for a semiarid biodiversity hotspot. Ecol. Soc. 14, 38.

Rivero, S., Villasante, S., 2016. What are the research priorities for marine ecosystem 
services? Mar. Policy 66, 104-113. doi:10.1016/j.marpol.2016.01.020

Sagie, H., Morris, A., Rofè, Y., Orenstein, D.E., Groner, E., 2013. Cross-cultural perceptions of ecosystem services: A social inquiry on both sides of the IsraeliJordanian border of the Southern Arava Valley Desert. J. Arid Environ. 97, 3848. doi:10.1016/j.jaridenv.2013.05.007

Sikor, T., 2013. The Justices and Injustices of Ecosystem Services. Routledge, London and New York.

Sikor, T., Baggio, J.A., 2014. Can Smallholders Engage in Tree Plantations? An Entitlements Analysis from Vietnam. World Dev. 64, S101-S112. doi:10.1016/j.worlddev.2014.03.010

Sikor, T., Martin, A., Fisher, J., He, J., 2014. Toward an Empirical Analysis of Justice in Ecosystem Governance. Conserv. Lett. 7, 524-532. doi:10.1111/conl.12142

Sodhi, N.S., Lee, T.M., Sekercioglu, C.H., Webb, E.L., Prawiradilaga, D.M., Lohman, D.J., Pierce, N.E., Diesmos, A.C., Rao, M., Ehrlich, P.R., 2010. Local people value environmental services provided by forested parks. Biodivers. Conserv. 19, 1175-1188. doi:10.1007/s10531-009-9745-9

Suich, H., Howe, C., Mace, G., 2015. Ecosystem services and poverty alleviation: A review of the empirical links. Ecosyst. Serv. 12, 137-147. doi:10.1016/j.ecoser.2015.02.005

van den Belt, M., Stevens, S.M., 2016. Transformative agenda, or lost in the translation? A review of top-cited articles in the first four years of Ecosystem Services. Ecosyst. Serv. 22, 60-72. doi:10.1016/j.ecoser.2016.09.006

Villamor, G.B., van Noordwijk, M., 2016. Gender specific land-use decisions and implications for ecosystem services in semi-matrilineal Sumatra. Glob. Environ. Chang. 39, 69-80. doi:10.1016/j.gloenvcha.2016.04.007

Zurba, M., Trimble, M., 2014. Youth as the inheritors of collaboration: Crises and factors that influence participation of the next generation in natural resource management. Environ. Sci. Policy 42, 78-87. doi:10.1016/j.envsci.2014.05.009 